International Journal of Civil Engineering and Technology (IJCIET)

Volume 11, Issue 6, June 2020, pp. 1-7, Article ID: IJCIET_11_06_001

Available online at https://iaeme.com/Home/issue/IJCIET? Volume $=11 \&$ Issue $=6$

ISSN Print: 0976-6308 and ISSN Online: 0976-6316

DOI: https://doi.org/10.34218/IJCIET.11.6.2020.001

(C) IAEME Publication

\title{
ORGANICS REMOVAL FROM DOMESTIC WASTEWATER UTILIZING PALM OIL CLINKER (POC) MEDIA IN A SUBMERGED ATTACHED GROWTH SYSTEMS
}

\author{
Baker N.S. Al-dhawi*, Shamsul R.M Kutty, Najib. M.Y. Almahbashi, Azmatullah Noor \\ and Ahmad H. Jagaba \\ Department of Civil and Environmental Engineering, \\ Universiti Teknologi PETRONAS, 32610 Perak, Malaysia \\ *Corresponding Author: bakeraldhawi@gmail.com
}

\begin{abstract}
To meet the discharge requirements, new treatment plants are designed as extended aeration systems with anoxic tanks to meet the new regulations. In this study, submerged attached growth made from palm oil clinker (POC), was introduced into conventional activated sludge systems. In the activated sludge system, aerobic and anoxic chambers were introduced to promote nitrification and denitrification. The performance of POC submerged system was monitored and compared to a biological activated sludge system. The performance on the removal of an organic was measured from COD, TSS, MLSS, and MLVSS. The rate of removal average for COD result of biomass improved $P O C$ in a $P O C$ reactor with attaching growth system $P O C$ mode is COD 30-50 mg/L, TSS 10-15 mg/L, MLSS 700-800 mg/L and MLVSS 600-700 mg/L for the POC reactor as attaching media. Therefore, using POC as an attach growth system can reduce the organic contaminant in effluent discharge.
\end{abstract}

Keywords: Attach growth system, Domestic wastewater, Organic removal, Palm Oil Clinker

Cite this Article: Baker N.S. Al-dhawi, Shamsul R.M Kutty, Najib. M.Y. Almahbashi, Azmatullah Noor and Ahmad H. Jagaba, Organics Removal from Domestic Wastewater Utilizing Palm Oil Clinker (POC) Media in a Submerged attached Growth Systems, International Journal of Civil Engineering and Technology, 11(6), 2020, pp. 1-7.

https://iaeme.com/Home/issue/IJCIET?Volume=11\&Issue $=6$

\section{INTRODUCTION}

Malaysia, one of most the world's most palm oil producers (PO) and manufactured many tonnages of palm oil produced per year. It was reported that industrial activities produced approximately forty million tons of oil palm waste. This waste of biomasses consists of oil palm trunk (OPT), empties fruits bunch (EFB) and oil palm frond (OPF). Many conventional 
ways of disposal are applied such as incineration and discharged to the lake. Due to the restrictions and regulations stated in the Environmental Quality Act 1974, the biomass is used to generate electricity by the combustion process. POC is a black solid waste by-product resulted from the combustion process [1]. The combustion process of oil palm fiber produced palm oil clinker (POC), Hence is generated in large-ranging around 150 and $350 \mathrm{~mm}$, then being crushed into a small size that can be fitted to use [2]. Physically the inner portions of POC are highly porous, which importantly contributes to the lightweight nature [1]. Reuse and minimize waste is conducted to achieve sustainability in the management and handling of waste. The by-product of the palm oil industry in Malaysia is five times the palm oil production. [2]. Those had created a sustainable issue regarding the disposal of palm oil products. It has been proved that palm oil clinker has great possibilities to be used as media in an attachment growth system in the domestic wastewater treatment system. In this study, the rate of removal of Chemical Oxygen Demand and Ammonia was used to determine the kinetics of wastewater parameter removal in the laboratory scale clinker continuous reactor wastewater treatment system [3]. Using waste by-products as media attach growth system comes to the aid to gain strength waste management to minimize environmental problems. The use of these wastes in other industries will be a creative and abundant way to increase productivity in each industry. Replacing cement and fine aggregates with untreated lignitecoal fly ash and rice husk ash (RHA), respectively, can help the agriculture industry save money by properly disposing of these rich by-products [1]. In this research, POC was taking from Felcra Berhad's palm oil mill. POC was obtained would be in variable sizes. In addition to conducting some engineering property tests to study the potential for POC utilization, also investigated the physical and chemical properties of (POC) across Malaysia using it as attached growth system aggregate. After the combustion process, the raw material POC material can be obtained in a mass of 100 to $500 \mathrm{~mm}$ [3]. Palm Oil Clinker considered as a steady and non-biodegradable material with the chemical compositions mixtures of $\mathrm{SiO} 2$, $\mathrm{Al} 2 \mathrm{O} 3$ and $\mathrm{Fe} 2 \mathrm{O} 3$ [4].

\section{METHODS AND MATERIALS}

\subsection{Material Collection, Preparation, and Characteristics of POC}

POC were collected from Felcra Berhad's palm oil mill plant located at Seberang Perak. POC were crushed and sieved to size between $37 \mathrm{~mm}$ and $28 \mathrm{~mm}$. After sieving, samples of the POC was immersed in domestic wastewater to observe the reaction of POC with domestic wastewater. Bulk weight, density, the surface area of POC was determining before immersed in the wastewater. This to test the difference in bulk weight of POC after immersed into the wastewater for a certain time interval [7].

\subsection{Experimental Methodology}

Two reactors designed and fabricated using Perspex to simulate a conventional activated sludge system as shown in Figure 1. POC were placed in one of the reactors in a cage to simulate a submerged attached growth system in a conventional activated sludge system. The cage was immersed in the reactor. Both reactors, POC and Control, consist of aeration zone and clarifier zone. Influent wastewater was collected from wastewater treatment plant in Universiti Tcknologi PETRONAS. A peristaltic pump used to feed the reactors at a flow rate of $10 \mathrm{~L} / \mathrm{d}$ for detention time of 24 hours. Sampling was taken every two days from effluent of POC and Control reactors and measured for chemical oxygen demand (COD) and TSS. Samples also were taken from the aeration reactor for both reactors to determine the mixed liquor suspended solids (MLSS) and mixed liquor volatile suspended solids (MLVSS) and measuring the sludge age and waste sludge. The tests were conducted according to the 
Standard Methods for the Examination of Water and Wastewater, 4500-NH3 B \& C, 15th Edition and APHA Method 4500-NO3: Standard Methods for the Examination of Water and Wastewater. Eckenfelder's First Order Model, Eckenfelder's Second-Order Model, McKinney's Model, Lawrence and McCarty's Model, Gaundy's Model, Kincannon and Stover's Models were used for predicting biokinetics of activated sludge process in both reactors.

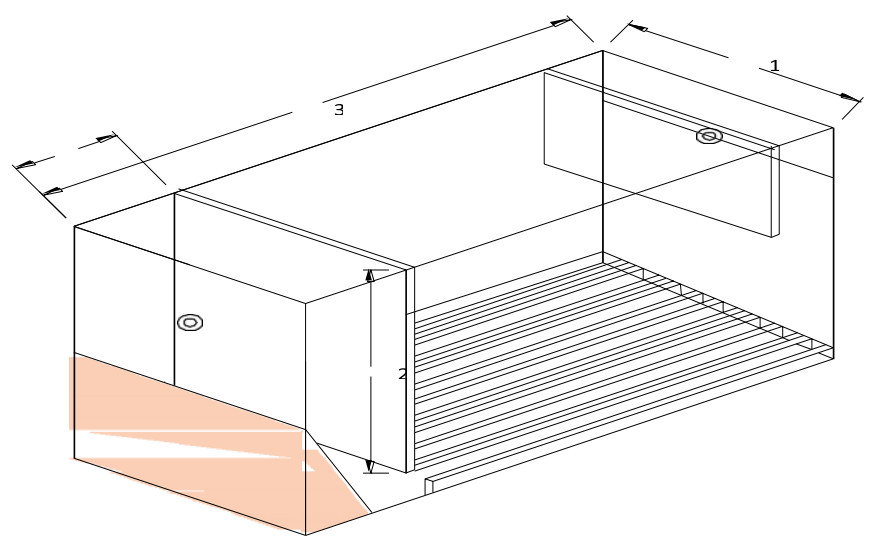

Figure 1 Properties of Palm Oil Clinker Reactor

\subsection{Procedure of Setup Reactor}

Biological treatment process of clinker reactor mode without palm oil clinker occurred in Control reactor. In POC reactor, the palm oil clinker is added as an attached media for clinker reactor mode. To provide an aerobic condition that is necessary for oxidation and nitrification process, air diffuser was placed in the bottom of the boxes [12], air diffusers also mix the organic matter inside the reactors [6]. In order microorganism achieved stability and steadystate, the reactor was subjected to an acclimatization period between 6 to 8 weeks. The result of effluent COD measurements used to determine the steady performance of the reactor. The total capacity of the individual reactor is 10 liter. In the study, one liter of biomass was added to nine-liter of wastewater [9] [10]. In POCR system established in POC reactor, aeration and sedimentation processes occurred and returned activated sludge biomass is neglected in this system [13]. Generally, the operating processes of the reactor are filling, reaction, precipitation, pouring out and idle. The filling process of reactor from $80 \%$ up to $95 \%$ conducted either during the inflow or added to the influent of wastewater. Biological reaction was activated during the feeding process by applying aeration and mixing processes. Sequentially, the removal of organics and nutrients occurring due to the activation of the biological process. After that, the reactor was subjected to the settlement process in which the solid is separated from the supernatant of clarified which is discharged as effluent [8].

\section{RESULTS AND DISCUSSION}

\subsection{COD Measurements}

Adequate amount of dog food was added every two days to the influent, therefore increment of COD reading was observed. Steady reading was achieved after one month. The COD results of influent raw domestic wastewater fluctuated gradually in the starting days. Therefore, the result of influent raw wastewater COD was about $500 \mathrm{mg} / \mathrm{L}$ to $600 \mathrm{mg} / \mathrm{L}$. The purpose of using POC as a submerged attach growth system in the reactor was to meet the standard of Malaysia [9]. As shown in Figure 2, COD effluent reading of the Control reactor, 
was $120 \mathrm{mg} / \mathrm{L} \mathrm{COD} \mathrm{which} \mathrm{is} \mathrm{higher} \mathrm{than} \mathrm{POC} \mathrm{reactor} \mathrm{with} \mathrm{an} \mathrm{average} \mathrm{reading} \mathrm{of} 35 \mathrm{mg} / \mathrm{L}$ COD. This verified the efficiency of using POC as a submerged attach growth system in enhancing the effluent quality of wastewater.

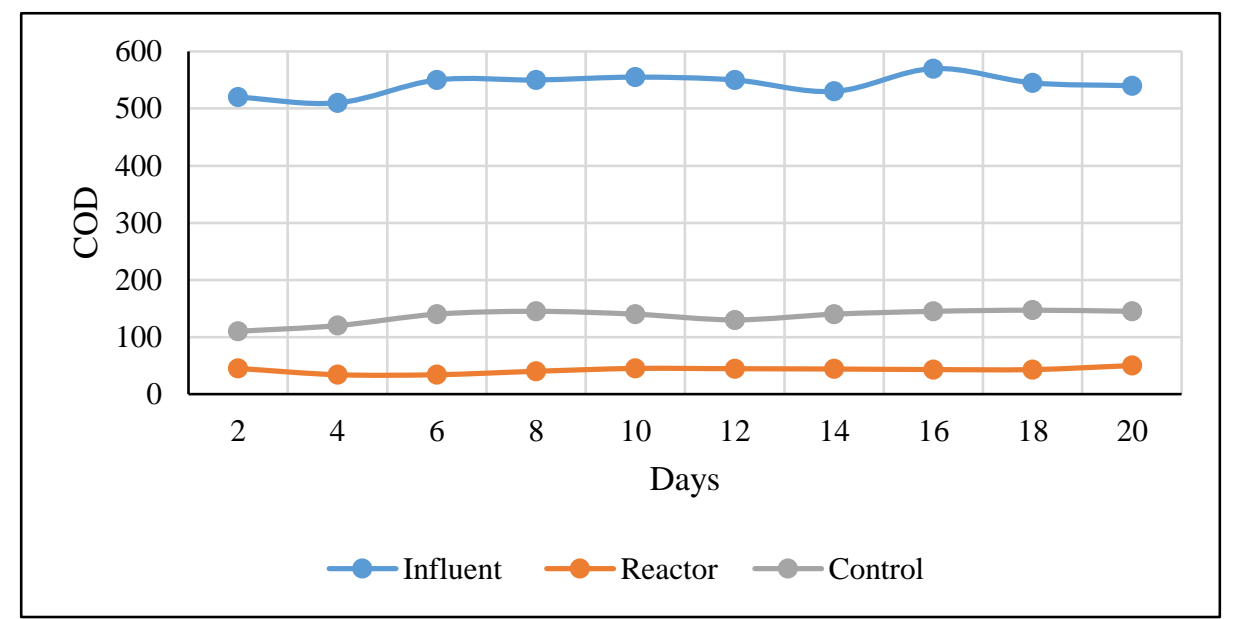

Figure 2 Graph of COD vs testing day

\subsection{TSS}

Total suspended Solids concentrations of influent and effluent were measured every two days for control and POC reactor. Fig. 3 showed that the influent TSS concentrations ranged between $40-50 \mathrm{mg} / \mathrm{L}$. Average TSS concentrations of control effluent and POC reactor effluent were $20 \mathrm{mg} / \mathrm{L}$ and $12 \mathrm{mg} / \mathrm{L}$ respectively. This could be interpreted as that Biomasses in Control are suspended biological while the Reactor are biological with attachment growth system to the (POCS) biofilm. POC as an attach growth system increases the contact surface area for biomass aggregate of palm oil clinker with influent raw wastewater. Hence, increase the performance of treatment and removing organic matter [4].

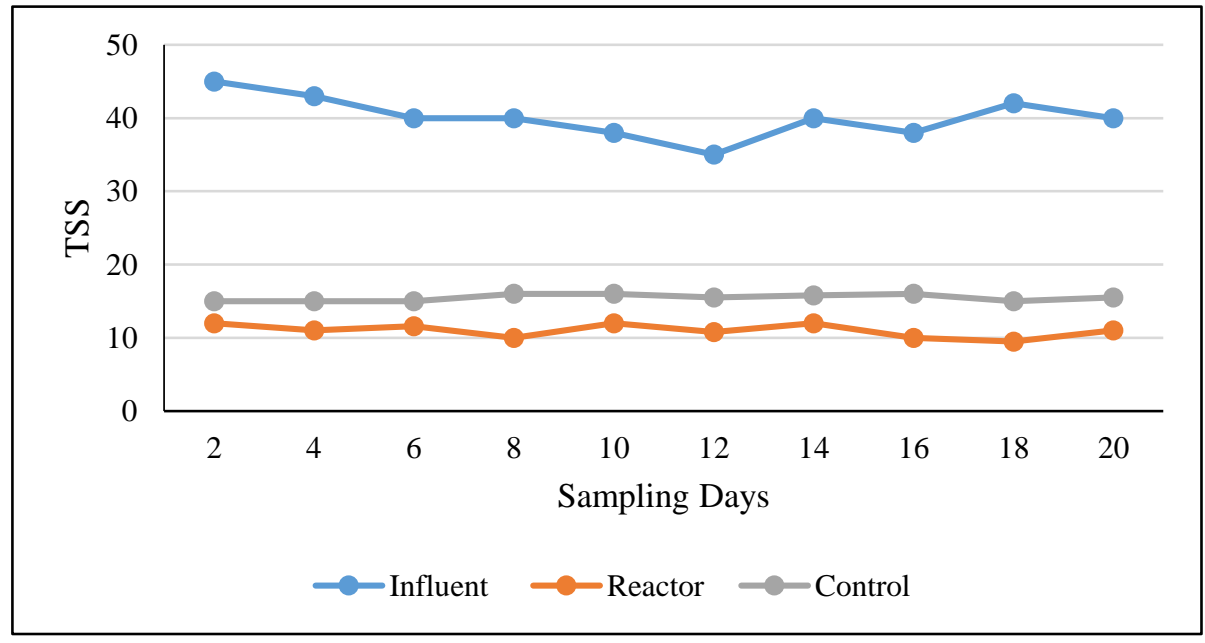

Figure 3 Graph of Total suspended soil vs Sampling days.

\subsection{MLSS and MLVSS}

MLSS is the concentration of suspended solids in aeration tank consist in 1L of the mixed liquor, and MLVSS represents the concentration of biomass in activated sludge consists in $1 \mathrm{~L}$ of the mixed liquor is flammable at $550^{\circ} \mathrm{C}$ [6]. MLSS and MLVSS concentration results were recorded over sampling days as illustrated in Figures 4 and 5 respectively. Biomass act 
as a biological treatment for domestic wastewater. The biomass in the Control reactor was suspended while in the POC reactor was suspended and attached growth system to POC media. Thus, the effectiveness of treatment and removal increased. MLSS results for POC reactor and Control reactor were ranged between $600 \mathrm{mg} / \mathrm{L}$ to $700 \mathrm{mg} / \mathrm{L}$ and $1000 \mathrm{mg} / \mathrm{L}$ to $1500 \mathrm{mg} / \mathrm{L}$ respectively. The reduction in MLSS and MLVSS of POC occurred because of biomass washing and stagnation within the POC [7]. During the experiment days, a few amounts of biomass was observed to be washed out with the effluent water. It was observed that the biomass was hold captive within the space between POC media and could not be mixed and suspended well.

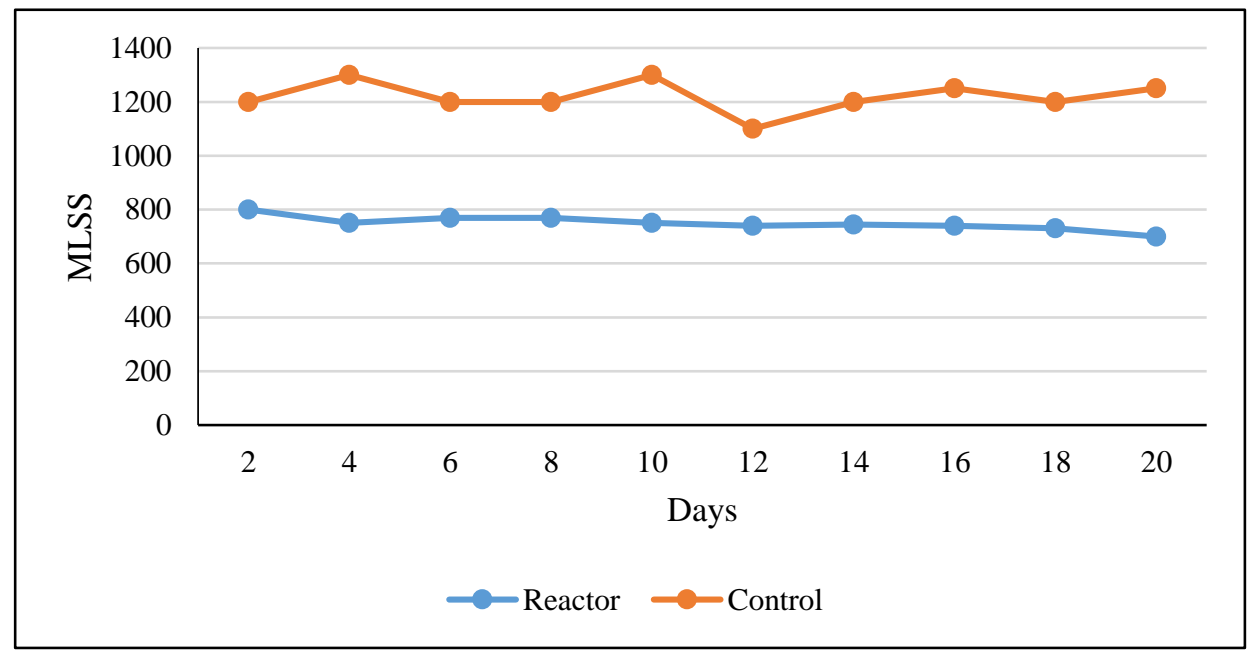

Figure 4 Graph of Mixed Liquor Suspended Solids vs Sampling days.

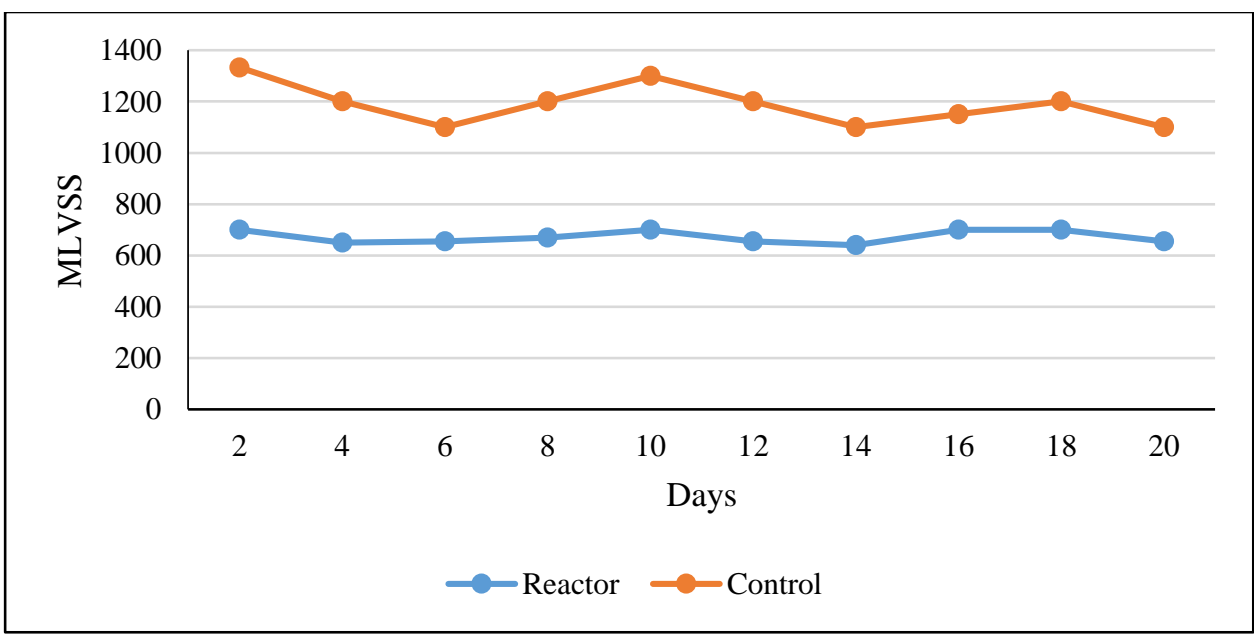

Figure 5 Graph of MLVSS vs Sampling days

The removal of COD using POC media per biomass is higher and steadier than the reactor, based on results finding from the effluent of the POC reactor quality with attached media. Kinetics coefficient finding for organics is $0.0056 \mathrm{mg}$ for a control and COD/mg and $0.01 \mathrm{mg}$ for a POC reactor as shown in Figure 6 and 7 respectively. 


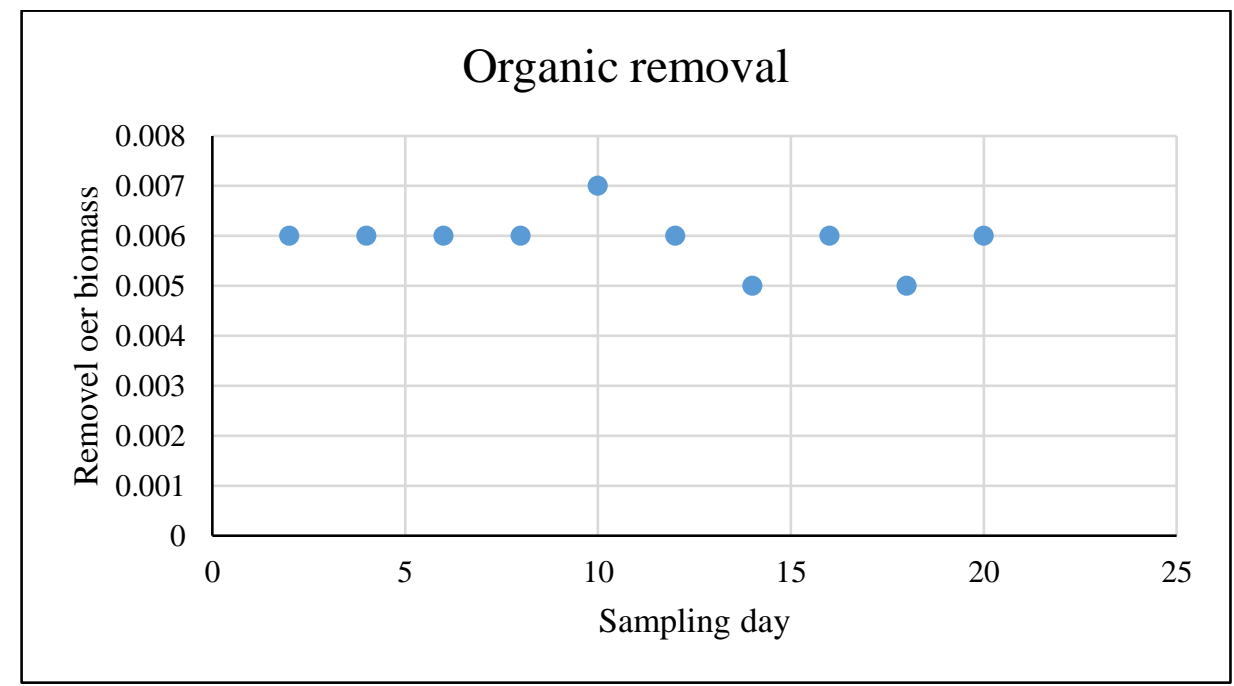

Figure 6 COD Removal Biomass (control)

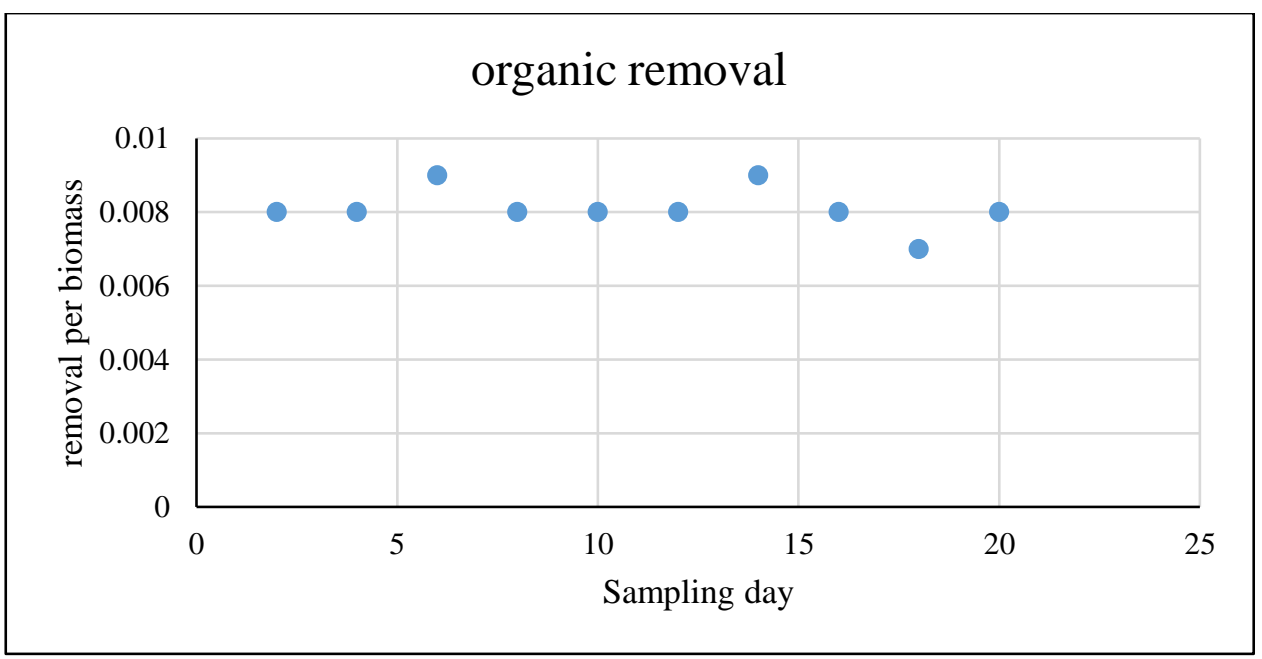

Figure 7 COD Removal with POC media per biomass (Reactor)

\section{CONCLUSION}

As the conclusion of this study conducted, the palm oil clinker system (POCS) as a waste of oil palm industrial boiler plants can be used as a media for submerged attached growth system wastewater treatment processes. POC serves as a media for aerobic microorganisms for the attachment of growth processes to organically remove domestic wastewater from UTP sewage treatment plants and can be used directly in continuous POC reactors.

Removal of organics by utilize palm oil clinker media in attach growth system was verified using COD, TSS, MLSS, and MLVSS test measurements fitted with standard methods. The removal ability of organic containment was reached by $90 \%$ to $95 \%$ removal. (POCS) source produced affordable and simple operations that are said to be more effective and efficient for small communities such as hostels, campuses, and villages.

For more reliable and accurate results data, experiment can be further investigated and improved by carried out sampling of discharge at different times. Changing in design parameters such as increasing the rate of feeding, reactor volume and time, operational problems such as biomass cleaning out could be developed which could lead to minimizing the functions of (POC) media as attached growth system in continuous reactor applications. 
Baker N.S. Al-dhawi, Shamsul R.M Kutty, Najib .M.Y. Almahbashi, Azmatullah Noor and Ahmad H. Jagaba

\section{ACKNOWLEDGEMENTS}

The authors would like to express their special thanks of gratitude to UTP and Fundamental Research Grant Scheme (FRGS) Agreement, Malaysia for their support. 015MA0-092

\section{REFERENCES}

[1] Abdullah, N., and Sulaiman, F. (2013). The oil palm wastes in Malaysia. In Biomass Now-Sustainable Growth and Use. InTech.

[2] Melin, T., Jefferson, B., Bixio, D., Thoeye, C., De Wilde, W., De Koning, J., Wintgens, T.J.D. (2006).

[3] Rogalla, F., Payraudeau, M., Bacquet, G., Bourbigot, M., Sibony, J., \& Filles, P. (1990). Nitrification and Phosphorus Precipitation With Biological Aerated Filters. 8(9): 65086530 .

[4] Karim, M.R., Hashim, H., Razak, H.A., Yusoff, S.J. (2015). Characterization of palm oil clinker powder for utilization in cement-based applications. 8(12): 8817-8838.

[5] Harrison, J.R., and Daigger, G.T.J.J. (1987). A comparison of trickling filter media. 679685.Kanadasan, J., Razak, H.A.J.M., \& Design. (2014). Mix design for self compacting palm oil clinker concrete based on particle packing. 56, 9-19.

[6] Karim, M.R., Hashim, H., Razak, H.A., Yusoff, S.J. C., \& Materials, B. (2016). Characterization of palm oil clinker powder for utilization in cement-based applications. $135,21-29$.

[7] Karim, M.R., Hashim, H., Razak, H.A., Yusoff, S.J. C., \& Materials, B. (2017). Characterization of palm oil clinker powder for utilization in cement-based applications. $135,21-29$.

[8] Krithika, D., \& Ligy, P. (2016). Treatment of wastewater from water based paint industries using submerged attached growth reactor. 107:31-41.

[9] Parveen, F., Rajeev, P., Hakimi, I., \& Norizan, E. (2010). Review of Current Palm Oil Mill Effluent (POME) Treatment Methods: Vermicomposting as a Sustainable Practice. 10(1):1190-1201.

[10] Nguyen, T.T., Ngo, H.H., Guo, W., Johnston, A., \& Listowski, A.J.B.T. (2009). Effects of sponge size and type on the performance of an up-flow sponge reactor in primary treated sewage effluent treatment.

[11] Raucher., \& Bob. (2015). The WateReuse Research Foundation is a nonprofitcharitable organization that conducts research to improve the treatment, distribution, and acceptance of reusing water.

[12] Christian, G., \& Karia, R. (2013). Wastewater treatment: Concepts and design approach.

[13] Tchobanoglous, G., Stensel, H., Tsuchihashi, R., Burton, F., Abu-Orf, M., Bowden, G., \& Pfrang, W. (2014). Metcalf and Eddy I AECOM. Wastewater engineering. treatment and resource recovery. In. New York. McGraw-Hill Book Company. 